\title{
Effects of extended fixed-interval training on reversed scallops*
}

\author{
HARRY J. CAPLAN, JOHN KARPICKE, and MARK RILLING $†$ \\ Michigan State University, East Lansing, Michigan 48823
}

\begin{abstract}
Two groups of pigeons were used to determine if different amounts of fixed-interval training with an added clock resulted in different local response rates when the clock was reversed. One group of seven pigeons received 120 reinforcements on a fixed-interval $90-\mathrm{sec}$ schedule, while the other group received 1200 reinforcements. Following training, the added clock was reversed in extinction. Reversed scallops were obtained for both of the groups. Only the group with extended training showed an increase in responding during the previously reinforced segment of the interval. This suggests the development of greater temporal control with extended training.
\end{abstract}

In a fixed-interval (FI) schedule of reinforcement, a response is reinforced only after a fixed amount of time has elapsed after a specific stimulus event, usually the start of the interval. The FI scallop, the typical pattern of responding produced by this schedule, is characterized by a pause after reinforcement, followed by a generally increasing rate of responding through the interval. The characteristics of the FI scallop may be altered through the use of an added clock, which is some dimension of a stimulus varying systematically in time. Added clocks have included a line projected on the response key which increased in length as the interval progressed (Ferster \& Skinner, 1957) and a light that increased in intensity (Donahoe, 1970). Donahoe demonstrated that typical FI responding developed more rapidly when an external clock was paired with the reinforcement schedule than when the clock was not present.

Following training with an added clock, reversing its direction is a method for determining whether responding is controlled by the stimuli of the added clock or by temporal stimuli. If reversing the clock reverses the FI scallop, responding is controlled by the clock. If, on the other hand, the clock is reversed and responding continues independently of changes in the clock stimuli, responding is assumed to be temporally controlled. A temporal discrimination may develop because the spacing of reinforcement is constant with respect to time.

Donahoe (1970) and Reynolds (1968) have suggested that sufficient conditions for the development of temporal control are met in FI schedules. Early in the interval, nonreinforcement results in a low rate of responding; while at the end of the interval, reinforcement results in a high rate of responding. A

*This investigation was supported in part by PHS Research Grant $1 \mathrm{R} 01 \mathrm{MH} 18342$ from the National Institute of Mental Health. The authors wish to thank T. L. Kodera for help in the preparation of the manuscript. Reprints may be obtained from Harry Caplan, Department of Psychology, Michigan State University, East Lansing, Michigan 48823.

$\dagger$ Now at Indiana University theoretical interpretation of FI responding is presented by Dews (1970), who discussed the temporal discrimination in terms of delay of reinforcement. He states that all of the responses in the FI schedule are followed by a reinforcer. Since the delays between each response and reinforcement differ, responses are strengthened differently. The responses closest to the reinforcer have the greatest strength and the responses farthest away from the reinforcer have the least strength. Therefore, the FI scallop can be considered a delay of reinforcement gradient.

As part of a more extensive study, Donahoe (1970) exposed a group of rats to an FI 120-sec schedule for 900 reinforcements, then reversed the clock following the 900th reinforcement. Although the rate of responding during the reversed clock was statistically different from the rate during the forward clock, the rate of responding during the test was lowest during the initial part of the interval and gradually increased. Thus, a reversed scallop was not obtained. Donahoe's test results suggested that responding in the FI schedule is controlled both by the clock and the temporal discrimination.

Donahoe hypothesized that, if two groups were run that differed in the amount of training, the group with the extended training would show greater temporal control than the group with a shorter amount of training. The present study examined differences in the rate of responding during a reversal of the clock as a function of the amount of training. While Donahoe used a group with 900 reinforcements, the present study compared groups with 120 and 1200 reinforcements. The two groups were run on a FI 90-sec schedule of reinforcement with an added intensity clock. Responding during each of six 15-sec segments was recorded.

\section{METHOD}

\section{Subjects}

Fourteen experimentally naive adult female White Carneau. pigeons, maintained at $80 \%$ of their free-feeding weights, served 


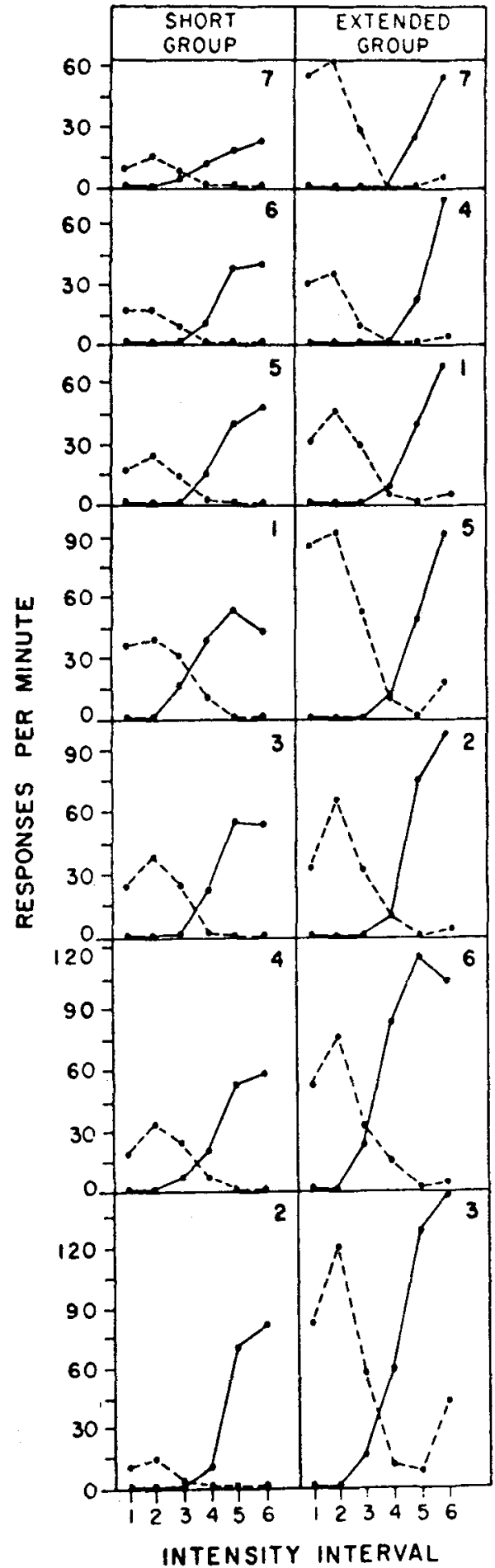

Fig. 1. Response rates for individual birds in both the short(left panel) and extended-(right panel) training groups. The solid lines represent the final training session, Day 6 and Day 60 for the short- and the extended-training groups, respectively. The dashed lines represent the test sessions. All points are means of 20 trials within a daily session.

as Ss. The Ss were assigned randomly to two experimental groups.

Apparatus

A Lehigh Valley Model 1519A pigeon chamber with three keys. a houselight above the middle key and an amber light at the rear of the chamber, was used. The middle key, illuminated by a Sylvania 24 ESB bulb, was wired in series with resistors of $0.47,150,270,470$, and $740 \mathrm{ohms}$. These values were judged by independent human observers as producing equal increments in the light intensity. The left- and right-side keys were covered throughout the experiment. Standard electromechanical programming equipment and data collection equipment were located in an adjacent room.

\section{Procedure}

The keypeck was shaped to a full-intensity green keylight to produce $3 \mathrm{sec}$ access to a mixed grain. Fifteen response contingent reinforcements were then presented for the following 15 responses. The response key was darkened during reinforcement during all phases of the study.

Six days of pretraining with each response reinforced were given to both of the groups. During each of the 6 days, 30 4.5-sec reinforcements were given for responding to a full-intensity green light.

During each of the subsequent training sessions, 20 FI 90 presentations were made, each separated by a $25-\mathrm{sec}$ timeout. During the timeout, the houselight and the keylight were turned off and the amber light at the rear of the chamber was illuminated. The $90-\mathrm{sec}$ intervals were divided into six $15-\mathrm{sec}$ increments of stimulus intensity, from least to most intense. The reinforced response occurred at the end of the interval in the presence of the brightest intensity of the light. The duration of the reinforcement was $4.5 \mathrm{sec}$. The short-training group received 6 days of training, and the extended-training group received 60 days of training.

On the day following the final training session, both of the groups received one testing session during extinction. The order of the stimulus intensities was reversed during the 20 presentations of the $90-\mathrm{sec}$ intervals, i.e., the stimuli were presented in the order of most to least bright. As in training, the $90-\mathrm{sec}$ presentations were separated by a $25-\mathrm{sec}$ timeout.

Responses were recorded during each of the six 15-sec segments of the 90 -sec intervals.

\section{RESULTS}

Figure 1 shows individual data for both the short-training group and the extended-training group. The solid lines represent the forward scallops of the final training sessions, and the dashed lines represent the reversed scallops observed during the test sessions. From left to right within each group, the data points are plotted as a function of the temporal presentations of stimuli, independently of the intensity sequences. Each data point is the response rate during the corresponding $15-\mathrm{sec}$ segments over the entire session.

All individuals in both the short- and the extended-training groups showed typical FI behavior during the final training session, Day 6 and Day 60 for the short-and the extended-training groups, respectively. All individuals in both of the groups exhibited reversed scallops during the test session. The extended-training group in general had a higher response rate during the final training and test sessions than did the short-training group.

Both groups showed a systematic increase in responding from the first to the second segment of the reversed scallops, except for Bird 6 of the short-training 
group, which had identical rates of responding in the first two segments. Both groups also showed a systematic decrease in responding from the second through the fifth 15-sec segment of the reversed scallops. Most importantly, only the extended-training group showed a systematic increase during the sixth segments, while the short-training group either decreased or had slight increases in responding. The Mann-Whitney U-tests showed that in all cases the sixth segment increases in responding in the extended-training group were significantly greater than the increases in the short-training group $(u=0, p<.01)$.

An examination of the slopes of the reversed scallops in the fifth and sixth segments reveals the magnitude of the effect. Whereas the fifth segment slopes of the shortand the extended-training groups showed no differences between the groups $(u=35, p>.50)$, the sixth segment slopes showed significant differences $(u=0, p<.01)$. Thus, while both groups were showing similar decreases as the interval progressed in the presence of the dimmer stimuli, only the extended-training group showed a consistent, substantial rate increase during the previously reinforced segment of the interval.

Figure 2 is the group average of the forward scallops for both the short- and the extended-training groups. The first two segments of the interval showed little

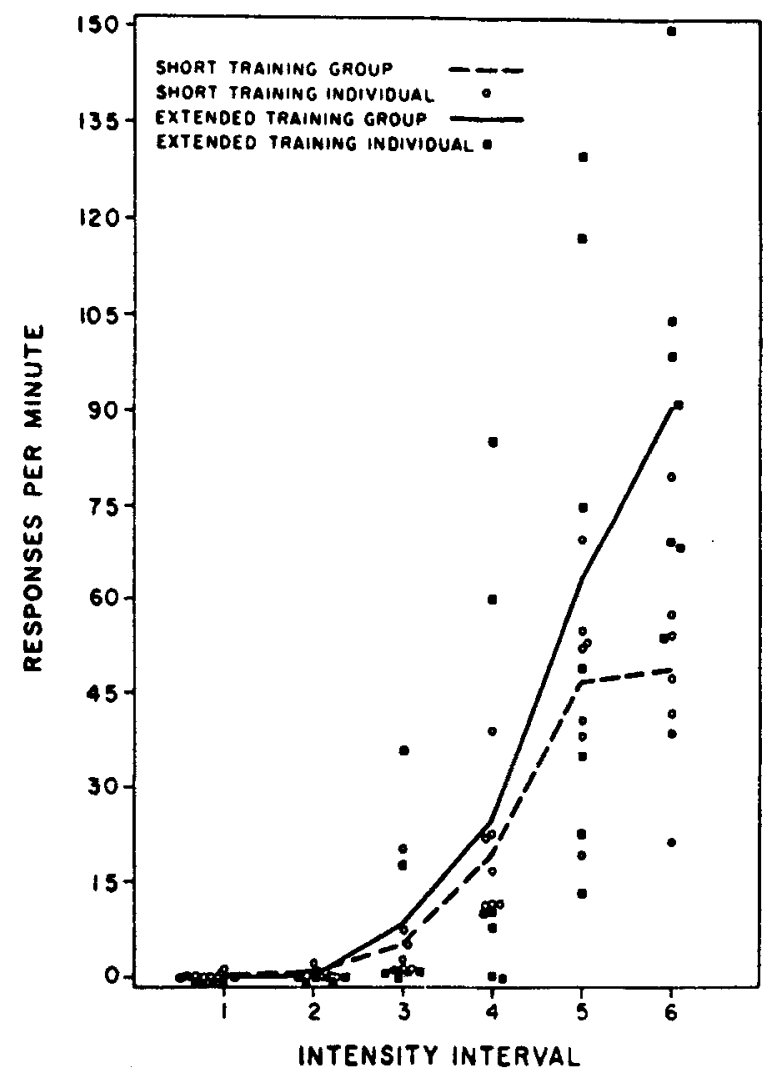

Fig. 2. Group data for the forward scallops. The solid lines represent the extended-and the dashed lines the short-training groups. Filled squares and empty circles represent the individuals of the extended-and short-training groups, respectively. All points are means of 20 trials within a session.

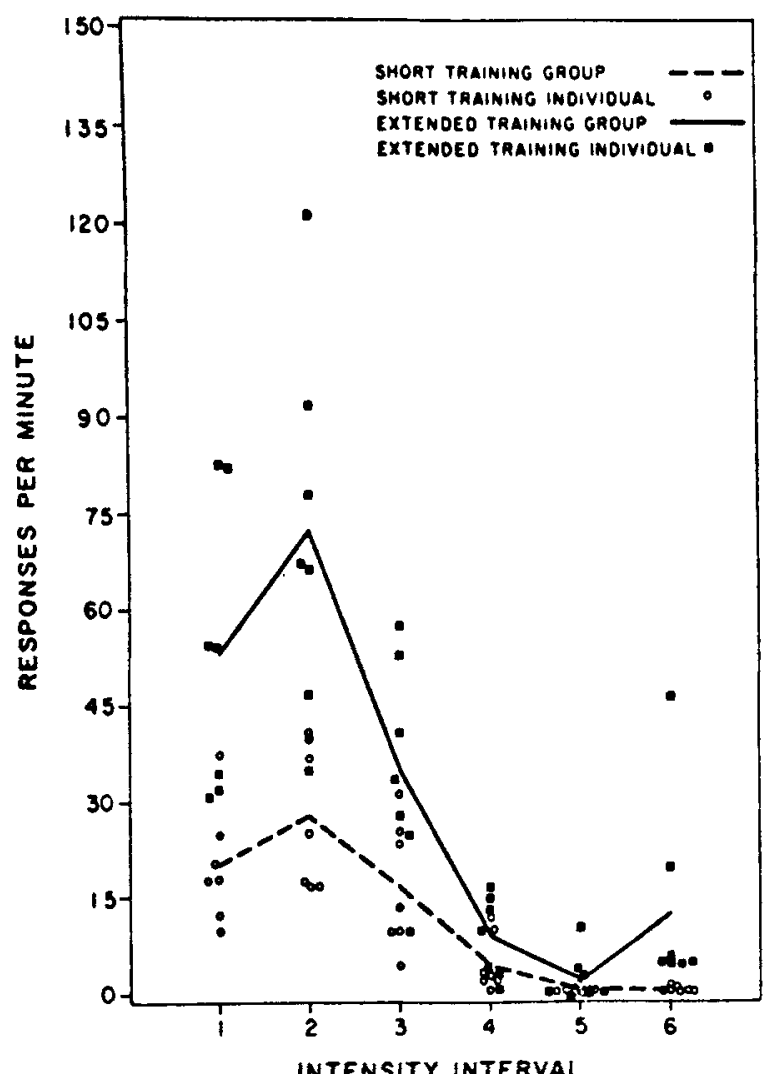

Fig. 3. Group data for the reversed scallops. The solid lines represent the extended-and the dashed lines the short-training groups. Filled squares and empty circles represent the individuals of the extended- and short-training groups. All points are means of 20 trials within a session.

difference between the groups, while the third through sixth segments showed increasingly higher response rates in the extended group than in the short-training group. Overlap of response rates occurred at all intensity intervals.

Figure 3 is the group average for both the extendedand short-training groups for the reversed scallops. The general form of the reversed scallops was similar for both groups, with the exceptions described above. Although the reversed scallops of the extended-training group generally exhibited higher response rates than the short-training group, overlap occurred at all of the segments except the previously reinforced sixth segment. During the sixth segment, all of the individuals in the extended-training group showed greater increases in responding, from the previous segment, than did the individuals in the short-training group. This was true for both slope and response rate change.

\section{DISCUSSION}

The results of the present study support Donahoe's theory that extended FI training produces an increase in temporal control over a shorter amount of training. During testing, the extended-training group showed a systematic increase in responding during the previously 
reinforced sixth segment, while the short-training group did not. This systematic increase occurred in the presence of at least two stimuli: an external stimulus that had been paired with reinforcement, a dim keylight, and temporal stimuli that had been paired with reinforcement at the end of the FI $90-\mathrm{sec}$ interval. Systematic decreases in response rates were observed in Segments 2.5 for all birds in both groups during the reversed scallops. In the penultimate segment, the slopes were the same for both groups. Since the increases observed in Segment 6 for the extended-training group were opposite in direction to the slope of the decreases observed both in the previous segments and in the short-training group, the results are not an artifact of the higher rates during extended training. Rather, the results indicate some sort of temporal control of responding in the final segment for the extended-training group only.

The control exerted by the clock stimuli was very powerful, for a reversal of the scallops did occur as a result of a reversal of the intensity dimension. Ferster and Skinner (1957, p. 277), using pigeons, also found a reversed scallop when they reversed an added clock correlated with an FI 30-min schedule. In contrast to the present study, however, they concluded that "The rate of responding is completely determined by the value of the slit on the key. Any stimuli from behavior or other stimuli also varying in time seem to exert no control." The present results demonstrate control by temporal stimuli in addition to the added clock at both the beginning and the end of the reversed scallop.

Ferster and Skinner (1957, p. 134) suggest that mediating behavior such as responding on the key is a possible mechanism for the temporal discrimination of the end of the interval. However, Dews (1962) found no disruption of the general FI pattern when responding was interrupted by repeated presentations of a stimulus correlated with extinction. Since the FI scallop remained intact in spite of the disruption of responding, Dews rejected response chaining as the mediating mechanism in FI responding. Response-mediated behavior is also inadequate to explain the present results. Both groups show a zero or decreasing rate of responding during the fifth segment of the reversed scallop. If the Ss were, in effect, counting the number of responses from the beginning of the interval, a zero or low rate of responding in the fifth segment of the interval should not occur.

Several investigators, Schneider (1969), Dews (1970), and Richards and Rilling (1972), have suggested that the initial proportion of the interval has inhibitory and aversive properties. Schneider (1969) states that the fixed-interval schedule is a two-state process. The initial state is a temporally discriminated extinction period, followed by a variable-interval component. Dews (1970) states that the temporal stimuli at the beginning of an FI schedule have "trace S-delta properties" and can affect responding at the early part of the interval. Richards and
Rilling (1972), using attack as a dependent measure of aversiveness, supported both the Schneider and Dews positions. They found that most of the FI attack occurred during the initial component of the interval.

In the present study, although the previously reinforced stimulus, the brightest light, was present during Segment 1 of the test intervals, the highest response rate occurred during Segment 2 for all of the brids except Bird 6 of the short-training group. Since the Ss' responses were never reinforced at the beginning of the interval during training, the temporal stimuli present during Segment 1 may have suppressed responding. That this effect was present in both the short- and the extended-training groups suggests that it develops earlier in training than the temporal effect, which occurred at the end of the interval in only the extended-training group. It is of interest that the single individual that showed a minimal suppression effect at the beginning of the interval belonged to the short-training group. Due to individual differences, perhaps not enough training had been given for this $S$ to show a large amount of response suppression. Thus, perhaps 200 rather than 120 trials would have been needed for this pigeon to show the effect as strongly as the other pigeons.

The response suppression might also be accounted for by the presence of the timeout. During training and testing, a timeout consistently preceeded a nonreinforcement period. The timeout may have come to signal the nonreinforced periods. Response suppression following a timeout may, therefore, be due to the information of nonreinforcement provided by the timeout.

\section{REFERENCES}

Catania, C. A. (Ed.), Contemporary research in operant behavior. Glenview, Ill: Scott, Foresman, 1968. Pp. 327-349.

Dews, P. B. The effect of multiple S-delta periods of responding on a fixed-interval schedule. Journal of the Experimental Analysis of Behavior, 1962, 5, 369-374.

Dews, P. B. The theory of fixed-interval responding. In W. N. Schoenfeld (Ed.), The theory of reinforcement schedules. New York: Appleton-Century-Crofts, 1970. Pp. 43-61.

Donahoe, J. W. Stimulus control within response sequences. In J. H. Reynierse (Ed.), Current issues in animal learning: $A$ colloquium. Lincoln, Nebr: University of Nebraska Press, 1970. Pp. 233-293.

Ferster, C. B., \& Skinner, B. F. Schedules of reinforcement, New York: Appleton-Century-Crofts, 1957.

Reynolds, G. S. A primer of operant conditioning. Glenview, Ill: Scott, Foresman, 1968.

Richards, R. W., \& Rilling, M. Aversive aspects of a fixed-interval schedule of food reinforcement. Journal of the Experimental Analysis of Behavior, 1972, 17, 405-411.

Schneider, B. A. A two state analysis of fixed-interval responding in the pigeon. Journal of the Experimental Analysis of Behavior, 1969, 12, 677-687.

(Received for publication March 26, 1973; revision accepted August 11, 1973.) 